\title{
Profile of Patients with Placental Abruption in
}

\section{Ultrasonography}

\author{
Nickolas Yugo Miyamura Namiuchi ${ }^{1}$; João Italo Fortaleza de Melo ${ }^{1}$; Luiz Dias Dutra ${ }^{1}$; Raphael Oliveira Ramos \\ Franco Netto ${ }^{2}$; Victor Augusto Ramos Fernandes ${ }^{2,3}$; Rebecca Corrêa Manfredini ${ }^{1}$; Messias Villa Mendonça ${ }^{1}$; \\ Fabio Rocha ${ }^{1}$; Juliana de Almeida Rodrigues Franco Netto ${ }^{2}$; Kayque Wellek Delgado do Amaral ${ }^{1}$; Gabriela \\ Kamigi Baggio Namiuchi ${ }^{1}$
}

${ }^{1}$ Cerdil-Center for Radiology and Diagnostic Imaging-Dourados -Brazil

${ }^{2}$ Tissue Morphology Laboratory-FMJ-Faculty of Medicine of Jundiaí-Jundiaí-Brazil

${ }^{3}$ N. Sra. Do Patrocínio University Center -Cruzeiro do Sul

Corresponding Author: Raphael Oliveira Ramos Franco Netto; raphael_fn@hotmail.com

Received 07 August 2020;

Accepted 20 August 2020;

Published 01 September 2020

\begin{abstract}
Objective: The objective of this study was to evaluate the incidence of placental abruption (PA) among nulliparous and multiparous women in the city of Dourados-MS Brazil. Materials and methods: Retrospective single-center cross-sectional study. 240 examinations of patients submitted to ultrasonography (USG) with medical indications for investigating PA were evaluated. Results: The average age was $28.6 \pm 6.38$, minimum 15 and maximum 43 years. The patients' weeks of pregnancy showed an average of $7.8 \pm 3.1$ minimum 4 and maximum 27 weeks. PA occurred in $66(27.7 \%)$ of the patients out of the 240 evaluated patients. Conclusion: The occurrence of PA in the studied population was high. There was no correlation between the occurrence of PA and the age of the patients. The relevance of family planning and adequate prenatal care in the early identification of risk factors for PA, as both contribute to reducing the incidence of unfavorable pregnancy outcomes.
\end{abstract}

Keywords: placental abruption; ultrasonography; pregnancy

\section{Introduction}

Placental Abruption (PA) is described and defined in the literature as a sudden fission, which can have a trauma or the implantation of the placenta in the uterus. In absolute numbers the global incidence is around $1 \%$. Currently available data demonstrate an occurrence of 6.5 per 1000 pregnant women ${ }^{[1]}$.

The causes of PA have not yet been fully elucidated or described. It can be subdivided into two large groups, with traumatic and non-traumatic characteristics. Traumatic ones can also be called mechanical, whereas their classification can have an internal and an external cause. Those with external traumatic causes are currently very limited, as they end up being restricted to serious accidents and relevant trauma. As for the causal factors in internal traumas, it is designated that the presence of a short umbilical cord length, rapid flow of polyhydramnios, abnormal increase in fetal movements, with a history of twin pregnancies; possible occurrence of postpartum uterine retraction and increased uterine tone, as the most frequent causes. As for non-traumatic causes, the literature emphasizes that of the predisposing factors, $\mathrm{PA}$ is the most important characteristic ${ }^{[2]}$.

Some factors have recently been described as having a risk correlation, among which are: arterial hypertension, poverty and malnutrition, multiple pregnancies, high maternal age, very poor obstetric history, patients who report of PA in previous pregnancy, previous cesarean delivery, patients with deficiencies in fetal development, chorioamnionitis, twin pregnancies and some factors related to lifestyle such as diabetes mellitus, smoking, alcoholism and drug abuse, with cocaine and heroin as the most mentioned. Some studies with initial results have pre-established new markers for this type of disease, with promising results as thrombomodulin, homocysteine and findings by Doppler of uterine vessels. Folic acid supplement, widely used in pregnancy, has not proven effectiveness in reducing PA ${ }^{[2-4]}$.

An important study tells that mothers affected by arterial hypertension are those of the main factors that lead to PA, the numbers reach $75 \%$ of cases. Having an assertive diagnosis of PA is a clinical prerogative, and ultrasonography (USG) is the classic auxiliary diagnostic method, as it can demonstrate the presence of retroplacental hematoma. However, it must be kept in mind that the lack of ultrasound findings do not rule out the occurrence of PA. Conventional USG through gray scale provides an assessment of PA, based on the demonstration of morphology, such as the absence of the subplacental anechoic zone that is normally found, hypoechoic placental echoes, abnormal bladder-uterine wall interface and pulsatile flow in hypoechogenic spaces. USG is an exam with low specificity, but it has a high positive predictive value $^{[3-6]}$. Therefore, the objective of this study was to evaluate the 
incidence of placental abruption (PA) among nulliparous and multiparous women in the city of Dourados-MS, Brazil.

\section{Materials and methods}

Retrospective cross-sectional, single-center study. 240 exams of patients submitted to USG with medical indications were evaluated for investigating PA occurrence. The exams were performed as a routine service through pre-established protocols, which follow national and international standards and consensus.

All patients underwent abdominal or transvaginal USG evaluation, using Doppler parameters in gray scale and color/power. The examination was performed in a 2-D color Doppler machine "Philips HD3" using a curved transducer 4.0-6.0 $\mathrm{MHz}$ or endovaginal probe 5.0-7.5 MHz. The Doppler power settings were in the level approved for fetal use. Gray-scale mode B USG was first used to track placental tissue, followed by color flow Doppler. The study was submitted to and approved by the Research Ethics Committee of UNIGRAN - Grande Dourados University. The inclusion criteria were patients with one or more pregnancies, patients with image and report, patients older than 15 years old and female, whereas the exclusion criteria were patients without signs of initial pregnancy, with negative beta HCG test and patients who had no available reports.

The exploratory analysis of the data occurred through the calculation of measures (mean, standard deviation, minimum, median, maximum, frequency and percentage) and construction of graphs. Student's t-test (or non-parametric Wilcoxon test). Comparison of quantitative variables between two groups. Pearson's correlation coefficient (r) Spearman (rho). Results that had a probability of type I error less than or equal to $5 \%(\mathrm{p} \leq 0.05)$ were considered statistically significant.

\section{Results}

In this study, 240 patients were evaluated, the mean age was 28.6 years \pm 6.38 , with a minimum age of 15 and a maximum age of 43 years (Table 1). The mean gestational weeks of the patients were $7.8 \pm 3.1$, with a minimum of 4 and a maximum of 27 weeks (Table 2). PA occurred in $66(27.7 \%)$ of the patients (Table 3 ). Abortions occurred in 13 (5.4\%) of the patients. When analyzing the differences between ages and the occurrence of PA, Pearson's correlation coefficient $(r)$ showed 0.985 with $p$ value 0.000 and Spearman (rho) 0.992 with $\mathrm{p}$ value 0.000 , demonstrating that there was a strong correlation between age variables and occurrence of PA.

When assessing whether the age factor was a predictive factor for PA, we did not observe significant differences between the age of patients with positive PA for those with negative PA, with a $\mathrm{p}$ value of 0.089 (table 3 ). The anatomical site most affected was the posterior wall of the uterus $(13.3 \%)$ of the sample.

Table 1: Descriptive Statistics - Age

\begin{tabular}{|l|l|l|l|l|l|l|}
\hline Variable & Total & Mean & Stan Dev & Minimum & Median & Maximum \\
\hline Age & $\mathbf{2 4 0}$ & $\mathbf{2 8 . 6}$ & $\mathbf{6 . 3}$ & $\mathbf{1 5}$ & $\mathbf{2 9}$ & $\mathbf{4 3}$ \\
\hline
\end{tabular}

Table 2: Descriptive Statistics Gestation in Weeks

\begin{tabular}{|l|l|l|l|l|l|l|}
\hline Variable & Total & Mean & Stan Dev & Minimum & Median & Maximum \\
\hline Gestation in Weeks & 24 & 7.8 & 3.1 & 4 & 7 & 27 \\
\hline
\end{tabular}

Table 3: Confidence Interval - Wilcoxon: Positive Age; Negative Age

\begin{tabular}{|l|l|l|l|l|}
\hline Sample & N & Median & CI for $\boldsymbol{\eta}$ & Confidence Reached \\
\hline Positive Age & 66 & 30 & $(28 ; 31.5)$ & $95.01 \%$ \\
\hline Negative Age & 172 & 28 & $(27 ; 29)$ & $94.99 \%$ \\
\hline
\end{tabular}

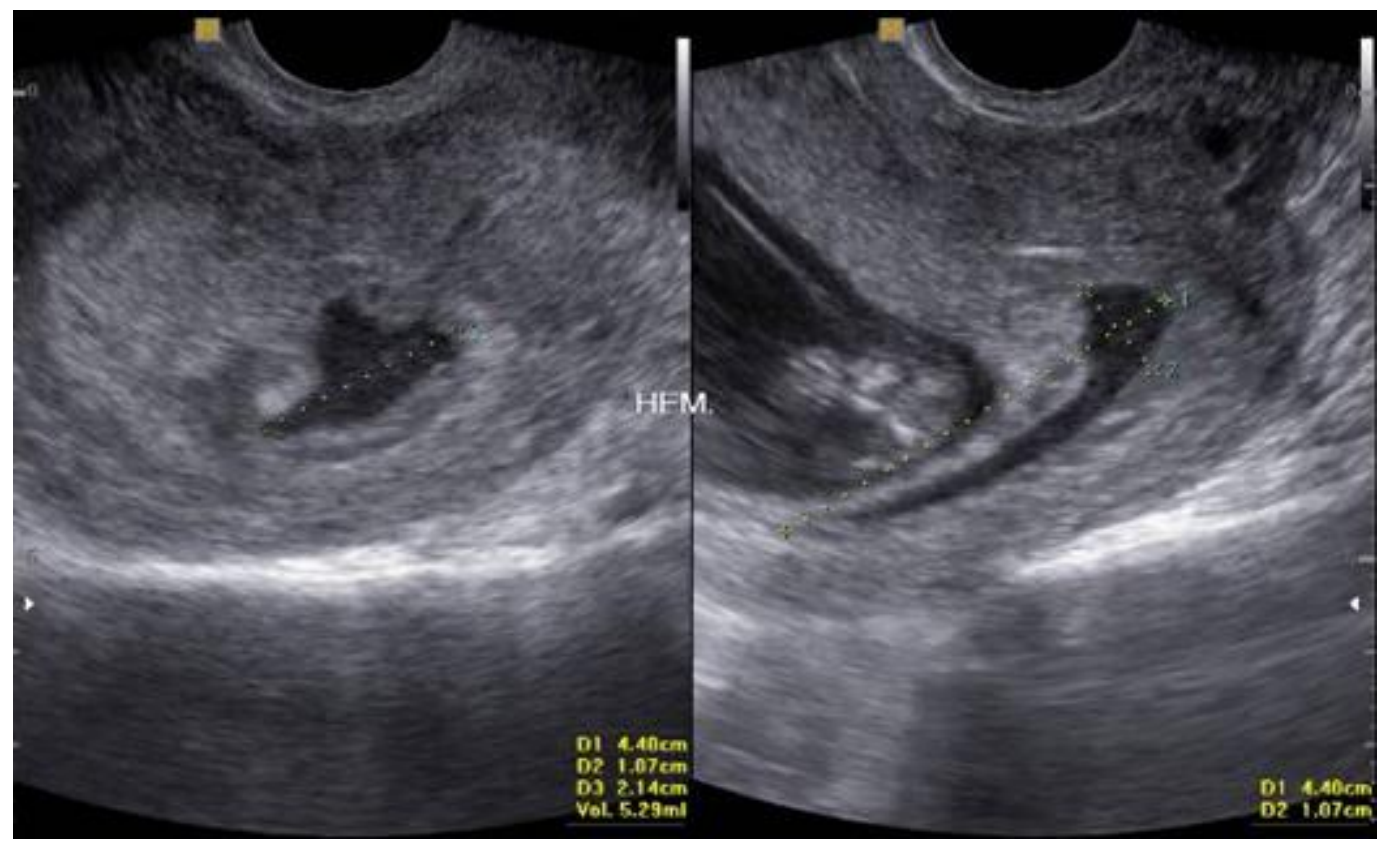

Figure 2: Ultrasonography of the uterus: Uterus with a pregnant appearance, with regular contours and preserved myometrial echotexture, with a gestational sac of funicular location and with regular contours. It presents an anechoic and heterogeneous area, located around the gestational sac, suggestive of hematoma. Closed cervix. It presents topical and single pregnancy of 10 weeks and 1 day and control of subchorionic hematoma, with a small increase in its dimensions. 


\section{Discussion}

The etiology of PA is not entirely clear about the high mortality rate among the affected pregnancies. There are numerous welldefined risk factors including: chronic systemic arterial hypertension, pre-eclampsia, drug use (cocaine), trauma, smoking, low socioeconomic status, single pregnant women ${ }^{[7]}$.

PA is a serious hemorrhagic entity in the second half of pregnancy, with high rates of perinatal mortality (around 25\%) andmaternal mortality. The prognosis of surviving fetuses becomes ominous, mainly due to prematurity and anoxia, with frequent sequelae injuries. The maternal prognosis can be compromised mainly due to the damage to multiple organs resulting from hypovolemic shock and the installation of coagulation disorders ${ }^{[8]}$.

Some studies demonstrate a high incidence rate of fetal deaths that had high rates of PA. In the study carried out, the occurrence in the group that was between 23-24 weeks of gestation, was observed that $17 \%$ the researchers did not observe differences related to the group that was born with 25 to 27 weeks of gestation $\mathrm{P}<0.001$. In our population, the mean number of weeks was 7.8, reaching a maximum 27 weeks. The authors reinforce that they found no significant difference in relation to gestational age ${ }^{[9-10]}$.

In another study, a group of researchers evaluated 430 patients aged 19 to 29 years, finding $13 \%$ with PA (56 patients out of 430). Researchers analyzed a total of 160 patients aged between 18 and 50 years, between 12 and 23 weeks of gestation, finding $10.4 \%$ with PA in their study. Miyazaki et al. $\left(2012^{[11]}\right)$ evaluated a group of 72 patients between 22 and 23 weeks of gestation, aged between 25 and 33 years, reported 15 to $22 \%$ with occurrence of PA. Linehan et al. $2016^{[12]}$ in his research evaluated a group of 42 pregnant women aged 19 - 42 years, between 13-22 weeks of gestation, found a $17 \%$ incidence of PA in their population. It is important to highlight that in this study $27.7 \%$ (66 of the 240) of the patients presented PA, corroborating with some studies presented above.

Studies in the literature have shown a high incidence of abortions related to the occurrence of PA, mainly occurring after 20 weeks of pregnancy. In the sample evaluated in this study it was found $5.4 \%$ had abortions in progress, however it is not possible to affirm that it was due to the occurrence of these cases of PA, due to the lack of clinical follow-up and greater data present in electronic medical records. It is not possible to rule out a relationship with this fact due to its considerable occurrence ${ }^{[13-15]}$.

\section{Conclusion}

It was possible to observe in this study that the occurrence of PA in the studied population was high. There was no correlation between the occurrence of PA and the age of the patients. There was no significant difference between the ages of the patients with the occurrence of PA. Thus the relevance of family planning and adequate prenatal care in the early identification of risk factors for $\mathrm{PA}$, which contributes to reducing the incidence of unfavorable pregnancy outcomes.

\section{Ethics approval and consent to participate}

The study was submitted to and approved by the Research Ethics Committee of UNIGRAN - Grande Dourados University.

\section{List of abbreviations}

Placental abruption (PA)

ultrasonography (USG)

\section{Data Availability}

All data in qualitative character, used by our work, as well as spreadsheets, images and others that support the results and conclusions of this study are readily available through the corresponding author.

\section{Conflicts of Interest}

The authors have no conflict of interest to declare.

\section{Funding Statement}

There was no financial support from any public or private institution for this research. The activities of this research were conducted using the authors in partnership.

\section{Authors' contributions}

The initial proposal was made by the NYMN and approved by all authors after submitting the research topic to a wide discussion and a better reformulation. JIFM conducted the literature review and collected all relevant data. KWDA and RORFN performed the data analysis. The Manuscript was written by NYMN, revised by all authors who agreed with its content and made the collective decision to submit it for consideration and possible publication

\section{Acknowledgments}

The authors of this study wish to officially thank the CERDIL Group's technical, operational and administrative team, especially Dr. Luiz Dutra, chief radiologist. To everyone in the pathological anatomy laboratory in the person of Dr. Fabio Rocha. We appreciate all the help during the period of data collection and execution of the works.

\section{References}

[1] Goetzl L. Adverse pregnancy outcomes after abnormal first-trimester screening for aneuploidy. Clin. Lab. Med. 2010; 30:613-628.

[2] Ananth C V., Keyes KM, Hamilton A, et al. An international contrast of rates of placental abruption: An age-period-cohort analysis. PLoS One 2015a; 10:1-15.

[3] Ananth C V., Keyes KM, Hamilton A, et al. An International Contrast of Rates of Placental Abruption: An Age-Period-Cohort Analysis. PLoS One 2015b; 10:e0125246.

[4] Ananth C V, Smulian JC, Demissie K, Vintzileos AM, Knuppel RA. Placental abruption among singleton and twin births in the United States: risk factor profiles. Am. J. Epidemiol. 2001; 153:771-8.

[5] Glantz C, Purnell L. Clinical utility of sonography in the diagnosis and treatment of placental abruption. J Ultrasound Med. 2002; 21(8):837-840. doi:10.7863/jum.2002.21.8.837

[6] Souza E, Camano L. Descolamento prematuro da placenta. Rev. Assoc. Med. Bras. 2006; 52:133-135.

[7] Ananth CV, Oyelese Y, Srinivas N, Yeo L, Vintzileos AM. Preterm premature rupture of membranes, 
intrauterine infection, and oligohydramnios: risk factors for placental abruption. Obstet Gynecol. 2004; 104:71-7.

[8] Cabar FR, Nomura RMY, Machado TRS, ZugaibM. Óbito fetal no descolamento prematuro da placenta: comparação entre dois períodos. Rev Assoc Med Bras 2008; 54(3):256-60.

[9] Newman DE, Paamoni-Keren O, Press F, Wiznitzer A, Mazor M, Sheiner E. Neonatal outcome in preterm deliveries between 23 and 27 weeks' gestation with and without preterm premature rupture of membranes. Arch. Gynecol. Obstet. 2009; 280:7-11.

[10] Ramsey PS, Lieman JM, Brumfield CG, Carlo W. Chorioamnionitis increases neonatal morbidity in pregnancies complicated by preterm premature rupture of membranes. Am. J. Obstet. Gynecol. 2005; 192:11621166.
[11] Miyazaki K, Furuhashi M, Yoshida K, Ishikawa K. Aggressive intervention of previable preterm premature rupture of membranes. Acta Obstet. Gynecol. Scand. 2012; 91:923-929.

[12] Linehan LA, Walsh J, Morris A, et al. Neonatal and maternal outcomes following midtrimester preterm premature rupture of the membranes: A retrospective cohort study. BMC Pregnancy Childbirth 2016; 16:1-7.

[13] Ghaheh HS, Feizi A, Mousavi M, Sohrabi D, Mesghari L, Hosseini Z. Risk factors of placental abruption. J. Res. Med. Sci. 2013; 18:422-6.

[14] Lydon-Rochelle M, Holt VL, Easterling TR, Martin DP. First-birth cesarean and placental abruption or previa at second birth(1). Obstet. Gynecol. 2001; 97:765-9.

[15] Misra DP, Ananth C V. Risk factor profiles of placental abruption in first and second pregnancies: heterogeneous etiologies. J. Clin. Epidemiol. 1999; 52:453-61. 